\title{
The Possibility of Directional Stability Improvement of Articulated Tool-Carriers
}

\author{
Marian J. Lopatka, Tomasz Muszynski
}

\begin{abstract}
Our research shown that there are two main reasons of poor directional stability of articulated tractorstoolcarriers: a small frame articulation which always occur due to different reason and limited perception of driver which has insensitivity zones of lateral and angular location. On this basis the principle for stabilization of steering system was worked out. In this paper the model of articulated tractor, assumption and result of simulating research such system are presented.
\end{abstract}

Index Terms-Articulated frame vehicle, directional stability, driver aid system, simulated investigation

\section{INTRODUCTION}

Tractors with articulated frame are widely used on construction sites as a basis machines for loaders, handlers, lift-trucks and other tool-carriers because their advantages such as: excellent leading of front attachment and good visibility during steering (attachment turns together with front frame and wheels), high maneuverability (short turn radius), high lifting capability (rigid axis), good mobility (the same tracks of front and rear axles during turning) and simple and durable construction. For this reasons has dominated wheeled equipment weight above 10 tons.

But as a automated or robotized equipment articulated tractors has one feature which limits their usefulness - it is poor directional stability of movement called snacking phenomenon. It is permanent deviations from one side to another and needed correction of path movement develop new one. So, the top speed is limited to 5$6 \mathrm{~km} / \mathrm{h}$ in remote or automated control systems.

Our research shown that there are two main reasons such behavior : a small frame articulation which always occur due to different reason [6], [8] and limited perception of driver which has insensitivity zones of lateral and angular location [7], [9].

On this basis the principle for stabilization of steering system was worked out.

This work was supported in part by the Polish Ministry of Science and Informatisation under Grant no.T00345346. The authors like to thank Polish Ministry of Science and Informatisation for the financial support.

M. J. Lopatka and T. Muszynski are with Military University of Technology, Kaliskiego Str. 2, 00-908 Warsaw, Poland (e-mail: mlopatka@wme.wat.edu.pl, tmuszynki@wme.wat.edu.pl)).

\section{CONCEPT OF STABILIZING SYSTEM}

Conducted at MUT research [6],[7] shows that main reasons of the snacking phenomenon are :

- $\quad$ initial turns of articulated frame (below $0,6^{0}$ ),

- residual steering moment in hydraulic cylinders.

In Ackerman steering system due to suitable geometry there are a few torques and forces that can acts straighten road wheels because of play in steering system and stabilize of vehicle movement [2]. Different geometry of steering and play absence in articulated tractors cause the stabilising function of steering system is fulfiled by the driver [7]. Their perception limits accurency of vehicle leding, directional stability of movement and top permitable speed. I order to improve directional stability od articulated tractors the limited sensitivity of human brain must be supported by driver aid system.

Becouse the driver sensitivity of angular deviation is limited to about $1^{0}$ and this is a main cause of poor directional stability of articulated tractor [9] - the driver aid system ought to straighten the frame and eliminate small turns of frame leading to deviations. For this reason new system consist sensor of frame articulation and additional hydraulic circuit for straighten the frame (fig.1). Such system should acts only when main steer valve not operates and their flow ought to be small as possible to not disturb main steering system operations in the case of damage and lowering the energy consumption and jerk accelerations.

As a first step the possibility of such system actions was investigated because the main problem for such solution is high torque of inertia of rotated front and rear parts of tractor. Additional hydraulic system was installed on 20 tons wheel loader and time domain characteristic was determined. For this test the gear pump with electric drive and $10 \%$ of nominal flow recommended by steering system manufacturer [3],[4],[11] was selected.

Results (fig. 2 and fig.3) shown that during $0,3 \mathrm{~s}$ time of operation pump achieved almost nominal flow $8 \mathrm{dm}^{3} / \mathrm{min}$ and frame turns about $0,5^{0}$ - value comparable to initial turns. It was positive because shown high speed of turn corrections almost without of any time lag and low power consumption at small pump delivery (it is very important from safety point of view because additional system working regardless of main steering system must be weaker) and there is possibility to operate in such system. 


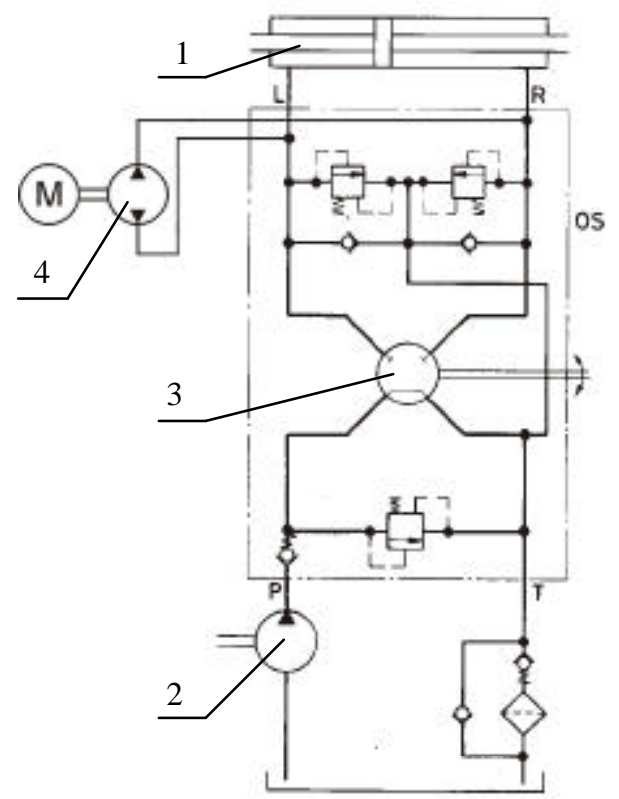

Fig. 1. Diagram of hydraulic steering system with additional driver aid system : 1 - steering cylinder, 2 - main pump, 3 - steering valve, 4 additional pump with electic drive

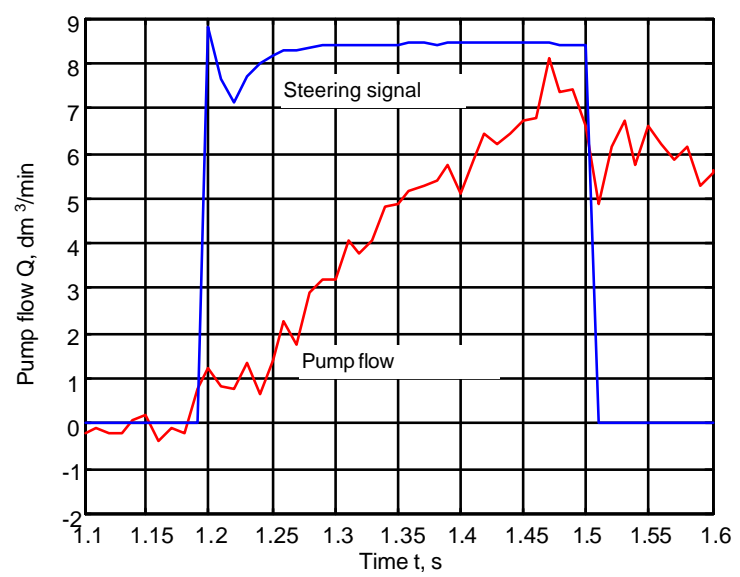

Fig. 2. Additional gear pump delivery during $20 \mathrm{t}$ loader frame turns

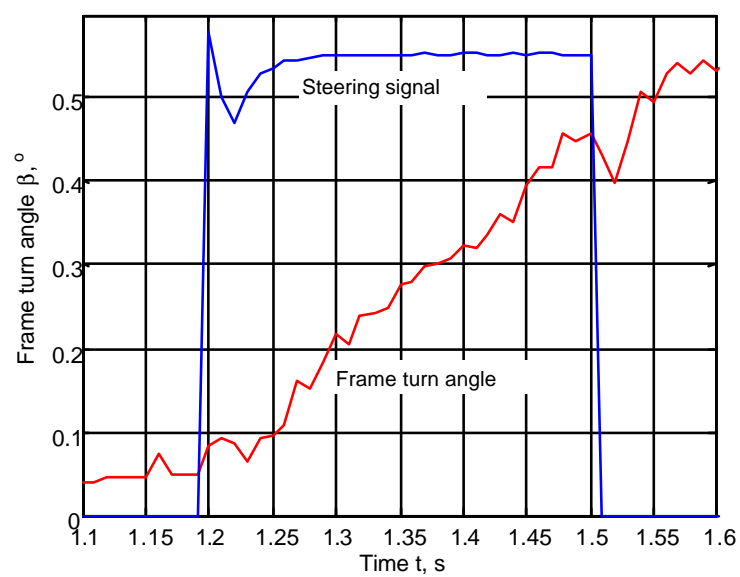

Fig. 3. Frame turns as influence of additional gear pump operation

\section{Model of ARticulated Tractor AS A SteERED VEHICLE}

For evaluating operational efficiency such system and estimating their main parameters the simulation model of articulated tractor as a steered vehicle was needed. Available models of articulated tractors for example $[1,5,10]$ are aimed on investigation of the critical speed phenomenon and for controlled movement simulation the new model was evaluated.

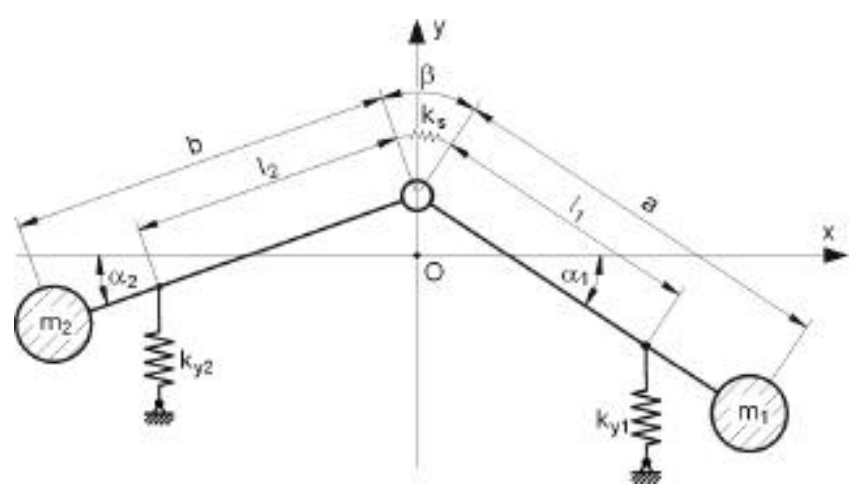

Fig. 4. Model of articulated vehicle frame turns

As a steering signal the frame turn angle $\beta$ (fig. 4) was selected. Because lack of suspension system in such tractors only tires and hydraulic steering system affect and disturb the trajectory of movement. For these reasons building a simplified linear model and taking for consideration the lateral stiffness of tires, their damping effect and hydraulic steering cylinders properties the equations describing such system are follow :

$$
\begin{aligned}
& m_{1} \ddot{y}-m_{1} a \ddot{\alpha}_{1}+m_{2} \ddot{y}-m_{2} b \ddot{\alpha}_{2}+k_{y 1}\left(y \cdot \alpha_{1} \cdot l_{1}\right)+k_{y 2}\left(y-\alpha_{2} \cdot l_{2}\right)= \\
& =-c_{1}\left(\dot{y}-a \dot{\alpha}_{1}\right)-c_{2}\left(\dot{y}-b \dot{\alpha}_{2}\right) \\
& J_{1} \ddot{\alpha}_{1}-m_{1} a \ddot{y}+m_{1} a^{2} \ddot{\alpha}_{1}+k_{S}\left(\alpha_{1}+\alpha_{2}-\beta\right)+k_{y 1}\left(\alpha_{1} l_{1}-y\right)= \\
& =c_{1} l_{1}\left(\dot{y}-a \dot{\alpha}_{1}\right)+c_{s}\left(\dot{\beta}-\dot{\alpha}_{1}-\dot{\alpha}_{2}\right) \\
& J_{2} \ddot{\alpha}_{2}-m_{2} b \ddot{y}+m_{2} b^{2} \ddot{\alpha}_{2}+k_{S}\left(\alpha_{1}+\alpha_{2}-\beta\right)+k_{y 2}\left(\alpha_{2} l_{2}-y\right)= \\
& =c_{2} l_{2}\left(\dot{y}-b \alpha_{2}\right)+c_{s}\left(\dot{\beta}-\dot{\alpha}_{1}-\dot{\alpha}_{2}\right)
\end{aligned}
$$

where:

$y$ - lateral deviation of pivot;

$a_{1}, a_{2}$ - angular deviation of front and rear parts of tractor;

$m_{1}, m_{2}$ - mass of front and rear parts of tractor;

$J_{l}, J_{2}-$ moments of inertia of front and rear parts of tractor;

$c_{l}, c_{2}$ - damping coefficients of front and rear tires;

$c_{s}$ - damping coefficient of hydraulic cylinders;

$k_{1}, k_{2}-$ stiffness coefficients of front and rear tires;

$k_{s}$ - stiffness coefficient of hydraulic cylinders;

$l_{1}, l_{2}$ - distance between front and rear axis and pivot;

$a, b$ - distance between front and rear center of gravity and pivot.

Assuming $A_{1}=\mathfrak{f}\left(\alpha_{1}\right), A_{2}=\mathfrak{£}\left(\alpha_{2}\right), Y=\mathfrak{f}(y), B=\mathfrak{l}(\beta)$ after Laplace's transformation - the frame movement described by angular deviation of front and rear parts of tractor and lateral deviation of pivot as forced by frame turn angle can be evaluated as : 
$Y=\frac{A_{1}\left(m_{1} a s^{2}+k_{y 1} l_{1}+c_{1} a s\right)+A_{2}\left(m_{2} b s^{2}+k_{y 2} l_{2}+c_{2} b s\right)}{m_{1} s^{2}+m_{2} s^{2}+k_{y 1}+k_{y 2}+c_{1} s+c_{2} s}$

$A_{1}=\frac{Y\left(m_{1} a^{2} s^{2}+k_{y 1}+c_{1} l_{1} s\right)+B\left(k_{s}+c_{s} s\right)-A_{2}\left(k_{s}+c_{s} s\right)}{J s^{2}+m_{1} a^{2} s^{2}+c_{1} l_{1} a s+c_{s} s+k_{s}+k_{y 1} l_{1}}$

$A_{2}=\frac{Y\left(m_{2} b^{2} s^{2}+k_{y 2}+c_{2} l_{2} s\right)+B\left(k_{s}+c_{s} s\right)-A_{1}\left(k_{s}+c_{s} s\right)}{J_{2} s^{2}+m_{2} b^{2} s^{2}+c_{2} l_{2} b s+c_{s} s_{1}+k_{s}+k_{y 2} l_{2}}$

In this case according to fig. 5 - the lateral velocity of articulated tractor movement is described as :

$$
\begin{aligned}
& v_{y 1}=v\left(\alpha_{1}-\delta_{1}+\varphi\right) \\
& v_{y 2}=-v\left(\alpha_{2}+\delta_{2}+\varphi\right)
\end{aligned}
$$

where: $v$ - vehicle velocity;

f - overall angular tractor deviation (fig. 5) for small angles of turns given by :

$$
\varphi=\frac{y_{1}-y_{2}}{L_{0}}
$$

where: $L_{0}-$ tractor wheel base;

$y_{1}, y_{2}$ - lateral wheels deviations;

$\mathrm{d}_{1}, \mathrm{~d}_{2}-$ slip angles front and rear wheels given by :

$$
\delta_{i}=\frac{k_{y i}\left(\alpha_{i} l_{i}-y_{0}\right)}{k_{\delta i}}
$$

where $: k_{\mathrm{di}}-$ cornering stiffness of tires.

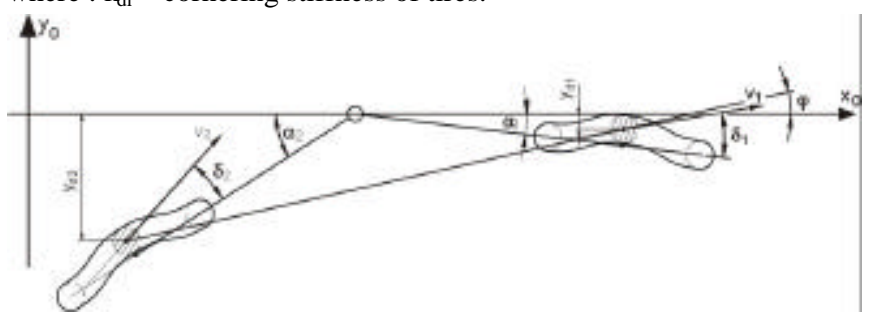

Fig. 5. Model of articulated vehicle movement

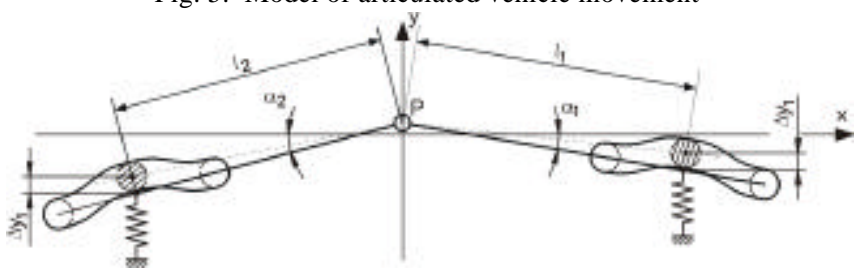

Fig. 6. Influence of tire stiffness on articulated vehicle movement

Bat lateral movement of pivot is smaller because lateral stiffness of tires (fig. 6) about :

$$
\Delta y_{i}=\delta_{i} \cdot r_{d}
$$

where : $r_{d}$ - radius of tire deformation (fig. 7).

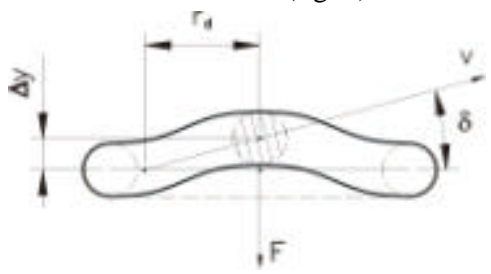

Fig. 7. Influence of tire stiffness on slip angle
And because lateral ground reactions are equal :

$$
R_{i}=k_{\delta i} \cdot \delta_{i}=k_{y i} \cdot \Delta y_{i}
$$

finally slip angles can be described as :

$$
\begin{aligned}
& \delta_{1}=\frac{\left(\alpha_{1} l_{1}-y_{0}\right)}{r_{d}} \\
& \delta_{2}=\frac{\left(\alpha_{2} l_{2}-y_{0}\right)}{r_{d}}
\end{aligned}
$$

Connecting these equations in Matlab-Simulink environment the model of articulated tractor as steered vehicle was build.

\section{MODEL VERIFICATION}

For estimating usefulness of presented model their verification on real articulated tractor was conducted. Tests depended on comparison and assessment of conformity registered and simulated trajectory of movement and lateral deviations of front and re ar parts of tractor. As exemplar the lateral deviations registered during $20 \mathrm{t}$ loader trials (fig. 8) was used. Force for simulation was worked out on the basis of registered frame steer angle (fig. 9) bat the curvature was simplified (fig. 10). All model parameters was determined for mentioned $20 \mathrm{t}$ articulated wheel loader (Tab. I). Calculated trajectory for these parameters and force are shown on fig. 11.

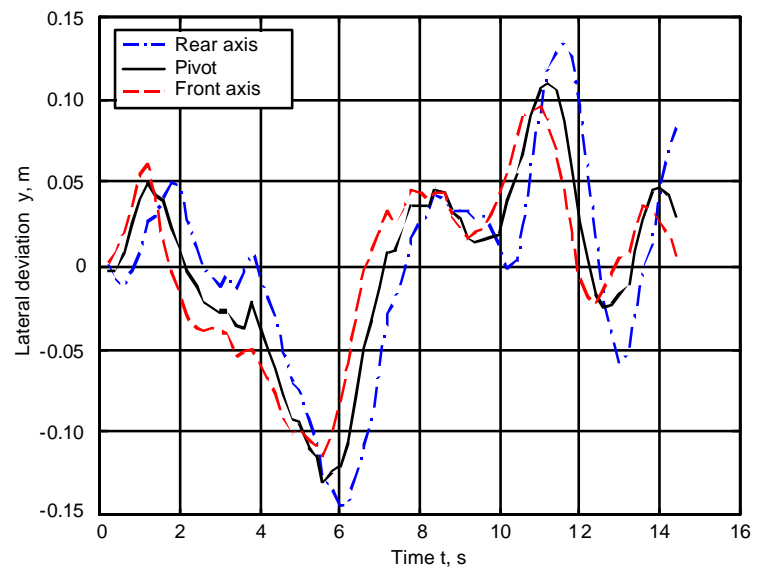

Fig. 8. Example of registered lateral deviations during articulated loader straight movement at speed $28 \mathrm{~km} / \mathrm{h}$

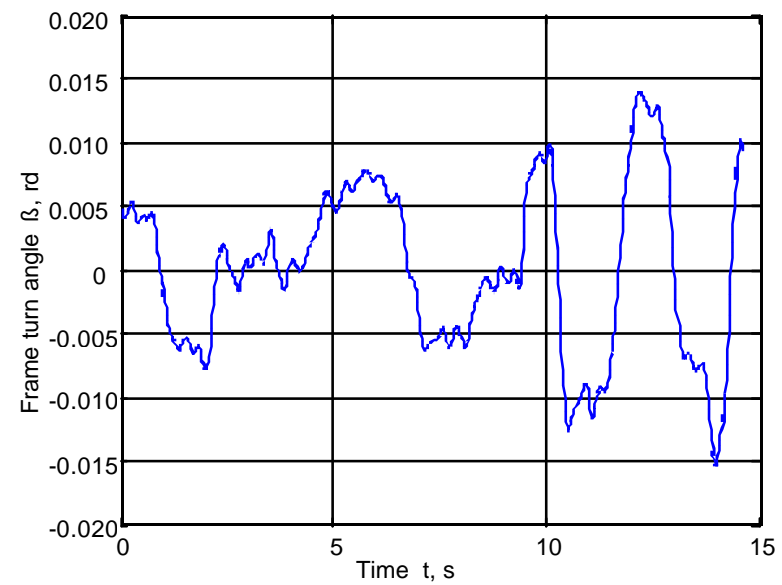

Fig. 9. Frame turn angle registered during articulated loader straight movement at speed $28 \mathrm{~km} / \mathrm{h}$ 
Conducted test shown not to high conformity because on simulated paths of movement front and rear axis there are no distinct difference which are observed in real motion. Lateral deviations of rear axle are about $5 \mathrm{~cm}$ higher - it is important because angular deviations are strongly depended on them.

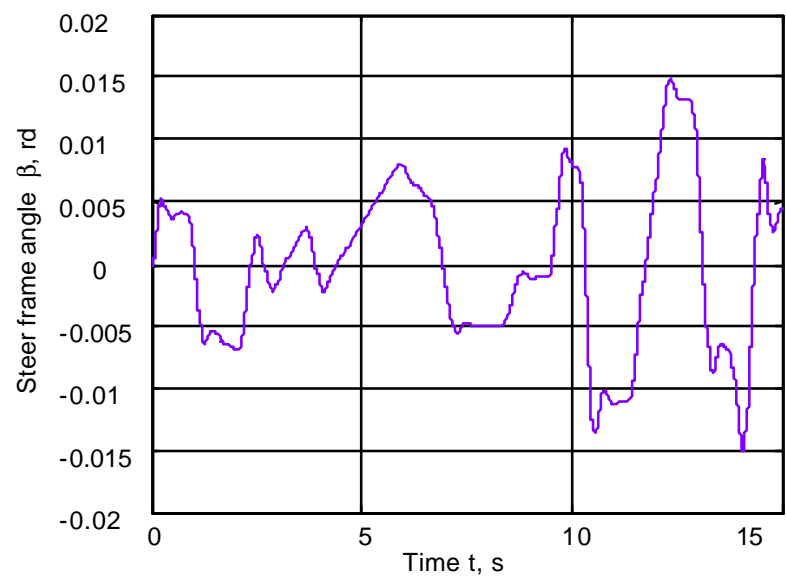

Fig. 10. Simplified force used for simulation of articulated loader straight movement at speed $28 \mathrm{~km} / \mathrm{h}$

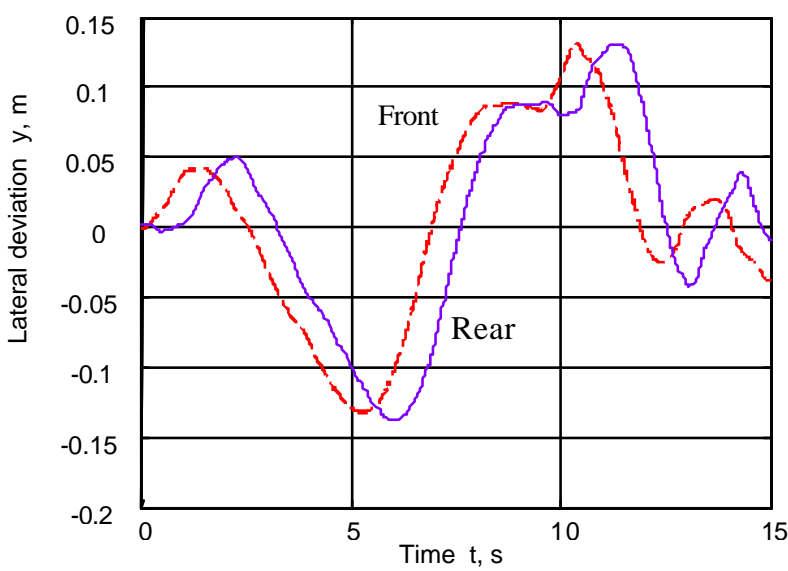

Fig. 11. Simulated lateral deviations during articulated loader straight movement at speed $28 \mathrm{~km} / \mathrm{h}$

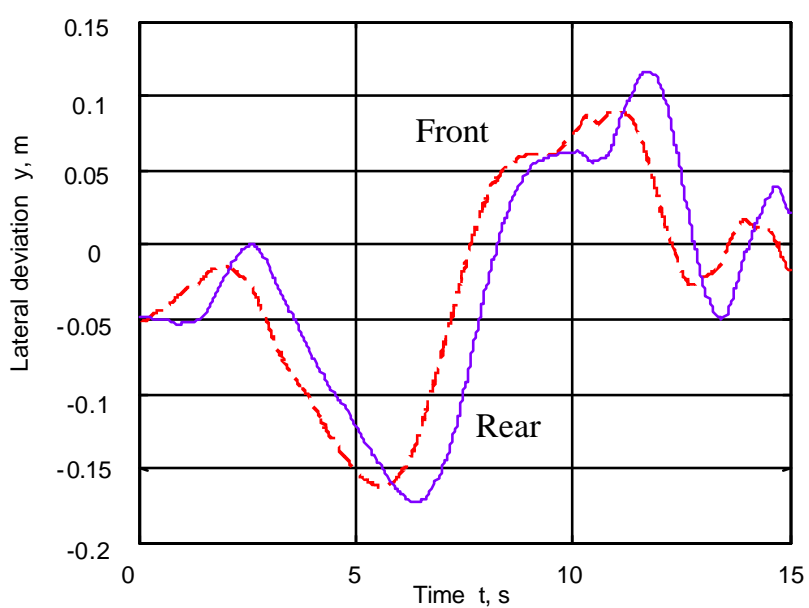

Fig. 12. Simulated lateral deviations during articulated loader straight movement at speed $28 \mathrm{~km} / \mathrm{h}$ with improvement model of articulated tractor
Table I. Parameters of articulated tractor model

\begin{tabular}{|c|c|}
\hline Parameter & Value \\
\hline$m_{1}$ & $9000 \mathrm{~kg}$ \\
\hline$m_{2}$ & $9500 \mathrm{~kg}$ \\
\hline$J_{l}$ & $42000 \mathrm{kgm}$ \\
\hline$J_{2}$ & $56000 \mathrm{kgm}$ \\
\hline$k_{1}$ & $8,1 \cdot 10^{5} \mathrm{~N} / \mathrm{m}$ \\
\hline$k_{2}$ & $4,1 \cdot 10^{5} \mathrm{~N} / \mathrm{m}$ \\
\hline$c_{1}$ & $5 \cdot 10^{4} \mathrm{Ns}^{2} / \mathrm{m}^{2}$ \\
\hline$c_{2}$ & $5 \cdot 10^{4} \mathrm{Ns}^{2} / \mathrm{m}^{2}$ \\
\hline$k_{s}$ & $224 \cdot 10^{5} \mathrm{Nm} / \mathrm{rd}^{2}$ \\
\hline$c_{s}$ & $1 \cdot 10^{5} \mathrm{Nms} / \mathrm{rd}^{2}$ \\
\hline$l_{1}$ & $1,57 \mathrm{~m}$ \\
\hline$l_{2}$ & $1,57 \mathrm{~m}$ \\
\hline$a$ & $1,70 \mathrm{~m}$ \\
\hline$b$ & $2,00 \mathrm{~m}$ \\
\hline
\end{tabular}

Undertaken analysis shown that reason of this small conformity is high moment of inertia of big size tires. Improved model (with influence of tire rubber high mass on tread) gives high accuracy of lateral deviations (fig. 12) and enabling investigation of driver aid system on simulations way.

\section{DRIVER AID SYSTEM EFFICIENCY CRITERION}

Vehicles with Ackerman steering system are characterized by low driver effort level compared to vehicles steered with frame turns [2]. Lowering frequency of driver actions is main goal for new system. To accomplish this target the knowledge about articulated tractor driver behavior is needed. Assuming that main factor causing driver reaction are lateral and angular deviations sensed by him - the articulated loader was rebuild. The steering wheel was moved to the front of vehicle and mounted above the axis to accelerating sensing of deviation and gives clear ties between deviations and driver reaction.

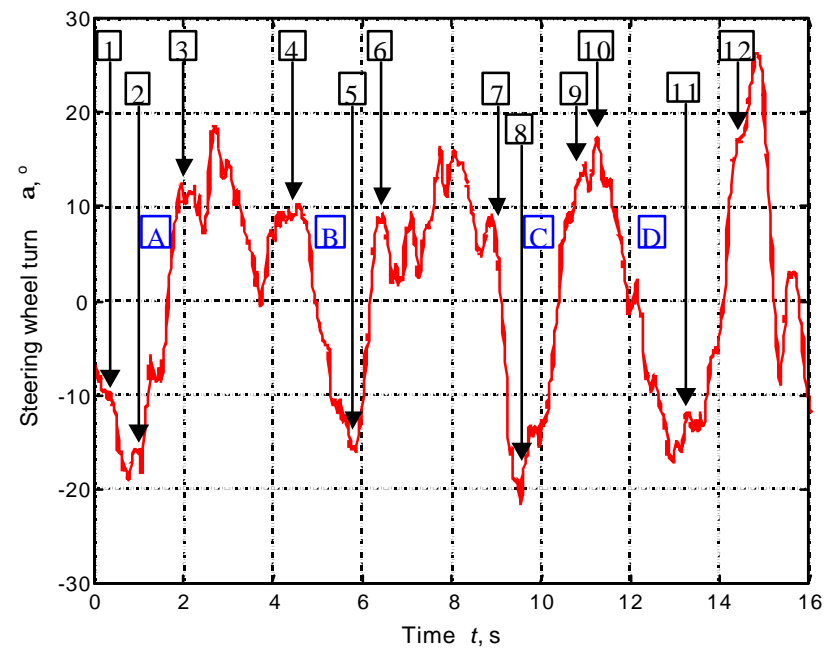

Fig. 13. Driver reactions as a steering wheel turn during modificated loader straight movement at speed $28 \mathrm{~km} / \mathrm{h}$

For such modificated loader investigation of driver reaction was conducted. They shown that after rebuilding there are period of high 
and low driver activity which enabling the selection of starting point of reaction - fig. 13 (for example point 4, 7, 10). Looking at lateral driver deviation curvature (fig. 14) it can be pointed that driver act when lateral deviation is about $\pm 0,2 \mathrm{~m}$ (and this value was achieved only two times) but correlation with starting point is not clear. Better correlation is seen on fig. 15 where is shown angular deviation of driver. Average achieved deviation is about $1,2^{\circ}$ and appear eight times in the same time. During car movement this deviation not exceed $0,5^{0}[2]$. It means that angular deviations are dominating in articulated vehicle movement and are crucial for driver effort. Eliminating residual frame angle with driver aid system the angular deviation can be limited and driver effort lowered.

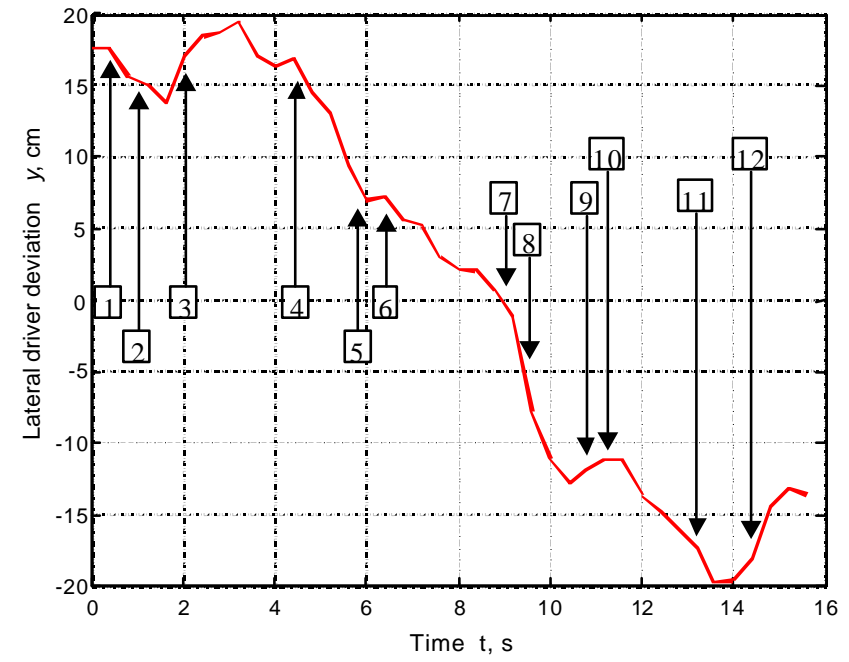

Fig. 14. Lateral driver deviations during modificated loader straight movement at speed $28 \mathrm{~km} / \mathrm{h}$

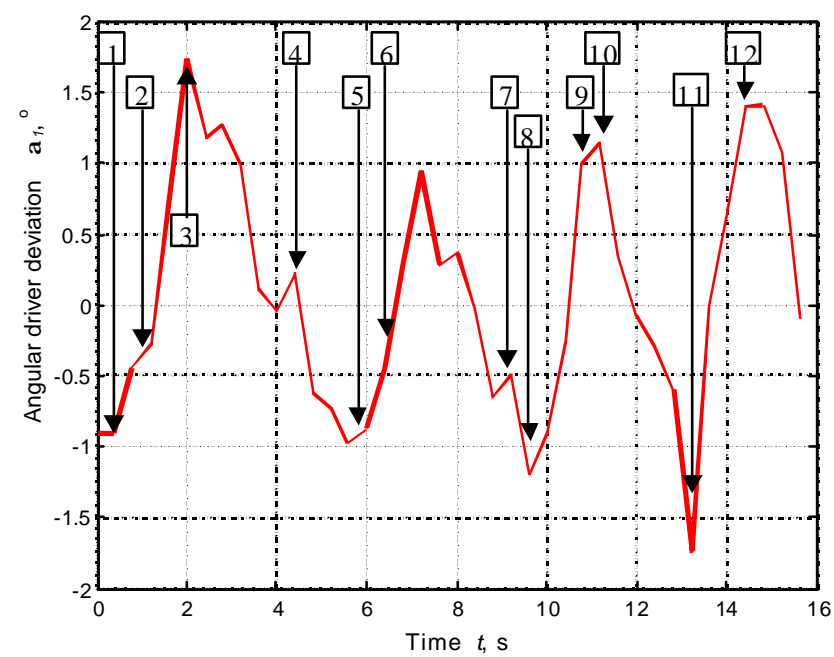

Fig. 15. Angular driver deviations during modificated loader straight movement at speed $28 \mathrm{~km} / \mathrm{h}$

Number footnotes separately in superscripts (Insert | Footnote). ${ }^{1}$ Place the actual footnote at the bottom of the column in which it is cited; do not put footnotes in the reference list (endnotes). Use letters for table footnotes (see Table I).
Efficiency of such system can be evaluated with time period from start to achieving one of determined limits of deviations : lateral $0,2 \mathrm{~m}$ and angular $1,2^{0}$.

\section{INVESTIGATION OF DRIVER AID SYSTEM EFFICIENCY}

Using worked out model and admitted criteria the simulating tests was conducted for additional hydraulic system operation with different pump delivery. Dynamic parameters of hydraulic system was determined on the basis previous conducted tests (fig. 2). As a starting position was assumed that residual frame turn angle is $0,6^{0}$ half value of evaluated perception limit and sensors of deviations are over front axis.

Results shown that to small flow in hydraulic system can't straighten frame in desired time (fig. 16) and although driver effort is lowered, angular deviation is still growing and stay main cause for driver reaction. Higher flow (fig. 17) enabling straighten frame before achieving angular deviation limit and stabilization of movement. In this case driver reaction is caused similar to another vehicles by lateral deviation.

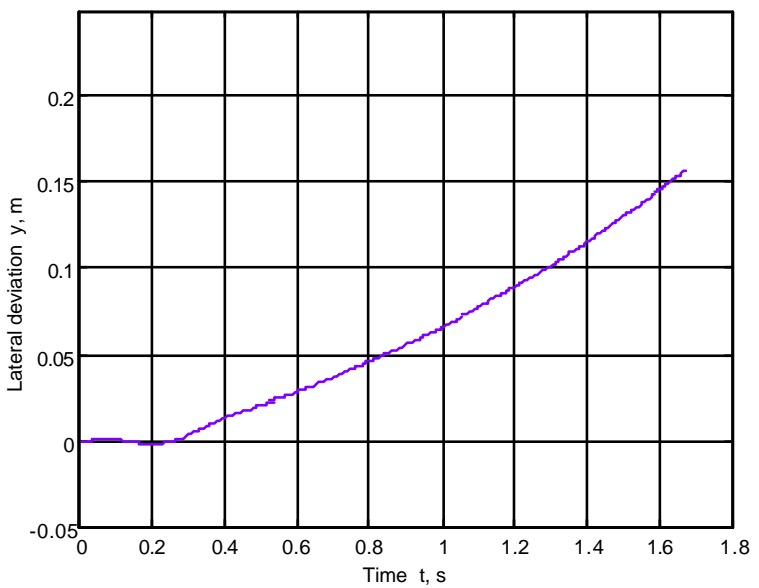

Fig. 16. Lateral driver deviations during loader straight movement at speed $60 \mathrm{~km} / \mathrm{h}$ and operating driver aid system with pump flow 4 $\mathrm{dm}^{3} / \mathrm{min}$

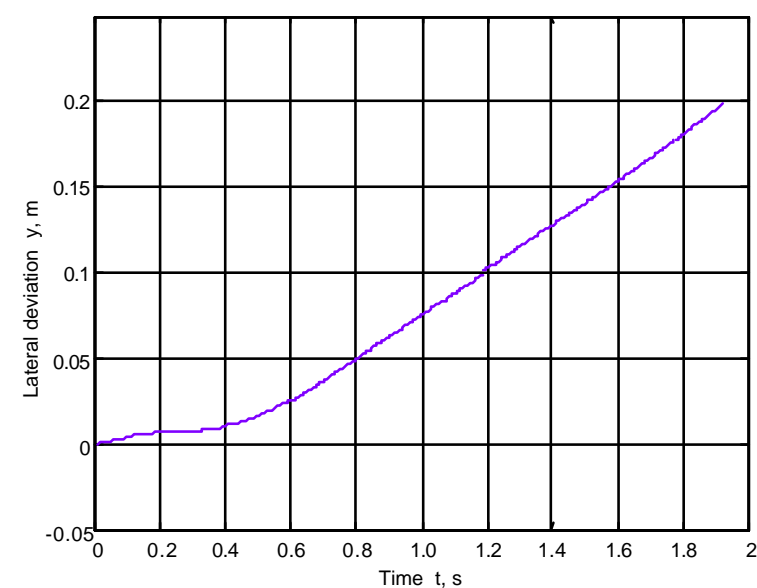

Fig. 17. Lateral driver deviations during loader straight movement at speed $60 \mathrm{~km} / \mathrm{h}$ and operating driver aid system with pump flow 10 $\mathrm{dm}^{3} / \mathrm{min}$ 
Efficiency of stabilizing system as function of pump delivery is presented in Table II. At relatively low speed (about $28 \mathrm{~km} / \mathrm{h}$ ) the system operating with $10 \mathrm{dm}^{3} /$ min nominal pump delivery can give high stability of movement - the driver reaction is needed after about $20 \mathrm{~s}$. But when sensors are connected with rear frame of tractor their acting is delayed and disrupt. So, the efficiency of stabilizing system in this case is limited - Table III.

Table II. Time to achieving deviation limits at sped $28 \mathrm{~km} / \mathrm{h}$ with sensors over front axis

\begin{tabular}{|c|c|c|}
\hline $\begin{array}{c}\text { Nominal } \\
\text { pump } \\
\text { delivery }\end{array}$ & $\begin{array}{c}\text { Time to } \\
\text { deviation } \\
y=0,2 \mathrm{~m}\end{array}$ & $\begin{array}{c}\text { Time to } \\
\text { deviation } \alpha= \\
1,2^{0}\end{array}$ \\
\hline$Q=10 \mathrm{dm}^{3} / \min$ & $20 \mathrm{~s}$ & - \\
\hline$Q=9 \mathrm{dm}^{3} / \min$ & $13 \mathrm{~s}$ & - \\
\hline$Q=8 \mathrm{dm}^{3} / \min$ & $11,6 \mathrm{~s}$ & - \\
\hline$Q=7 \mathrm{dm}^{3} / \min$ & $7,3 \mathrm{~s}$ & - \\
\hline$Q=6 \mathrm{dm}^{3} / \min$ & $7,2 \mathrm{~s}$ & - \\
\hline$Q=5 \mathrm{dm}^{3} / \min$ & $27 \mathrm{~s}$ & - \\
\hline$Q=4 \mathrm{dm}^{3} / \min$ & $4,4 \mathrm{~s}$ & - \\
\hline$Q=3 \mathrm{dm}^{3} / \min$ & $3,6 \mathrm{~s}$ & - \\
\hline$Q=2 \mathrm{dm}^{3} / \min$ & $2,9 \mathrm{~s}$ & - \\
\hline$Q=1 \mathrm{dm}^{3} / \min$ & $-(4 \mathrm{~cm})$ & $1,54 \mathrm{~s}$ \\
\hline $\mathrm{Q}=0$ & $-(2 \mathrm{~cm})$ & $1,36 \mathrm{~s}$ \\
\hline
\end{tabular}

Table III. Time to achieving deviation limits at sped $28 \mathrm{~km} / \mathrm{h}$ with sensors over pivot and connected with rear frame

\begin{tabular}{|c|c|c|}
\hline $\begin{array}{c}\text { Nominal } \\
\text { pump } \\
\text { delivery }\end{array}$ & $\begin{array}{c}\text { Time to } \\
\text { deviation } \\
y=0,2 \mathrm{~m}\end{array}$ & $\begin{array}{c}\text { Time to } \\
\text { deviation } \alpha= \\
1,2^{0}\end{array}$ \\
\hline$Q=10 \mathrm{dm}^{3} / \min$ & $2,45 \mathrm{~s}$ & - \\
\hline$Q=9 \mathrm{dm}^{3} / \min$ & $2,34 \mathrm{~s}$ & - \\
\hline$Q=8 \mathrm{dm}^{3} / \min$ & $2,33 \mathrm{~s}$ & - \\
\hline$Q=7 \mathrm{dm}^{3} / \min$ & $2,13 \mathrm{~s}$ & - \\
\hline$Q=6 \mathrm{dm}^{3} / \min$ & $2,2 \mathrm{~s}$ & - \\
\hline$Q=5 \mathrm{dm}^{3} / \min$ & $2,5 \mathrm{~s}$ & - \\
\hline$Q=4 \mathrm{dm}^{3} / \min$ & $-(16 \mathrm{~cm})^{*}$ & $1,67 \mathrm{~s}$ \\
\hline$Q=3 \mathrm{dm}^{3} / \min$ & $-(14 \mathrm{~cm})^{*}$ & $1,50 \mathrm{~s}$ \\
\hline$Q=2 \mathrm{dm}^{3} / \min$ & $-(14 \mathrm{~cm})^{*}$ & $1,45 \mathrm{~s}$ \\
\hline$Q=1 \mathrm{dm}^{3} / \min$ & $-(13 \mathrm{~cm})^{*}$ & $1,40 \mathrm{~s}$ \\
\hline$Q=0$ & $-(10 \mathrm{~cm})^{*}$ & $1,17 \mathrm{~s}$ \\
\hline
\end{tabular}

\section{CONCLUSION}

In the case of articulated tractor opposite to Ackerman steered vehicle angular deviations are dominated. Moreover conducted tests shown that human perception is limited and deviation can reach : lateral $0,2 \mathrm{~m}$ and angular $1,2^{0}$.

Carried out research shown that limitation of snacking phenomenon during movement of articulated tool-carriers with driver aid system is possible. The principles of their operation was verificated on simulation way. Developed unique model of articulated tractor as steered vehicle shown full usefulness for such simulation and can be used in future works on developing the electronic control system and sensors necessary for demonstrator building.

Proposed system can increase productivity of articulated equipment due to higher travel speed but it is strongly recommended to connect sensors of deviation with front frame of vehicle.

\section{References}

[1] Borkowski W., Konopka S., Prochowski L.: Dynamika maszyn roboczych. WNT, Warszawa1996

[2] Chaczaturow A.A.: Dinamika sitemy - doroga-szina-awtomobilwoditiel. Maszinostrojenie, Moskwa 1976

[3] Danfoss: Hydrostatic steering components. Hydrostatic and hydromechanical steering systems. HK.20.B1.02

[4] Eaton : Steering Control Units and Torque Generators. Char-Lynn Power Steering No 11-872

[5] Iwanow A.N., Grigoriew S.N., Korzin A.B.: Analiz kriwolimiejnowo dwirzenia mnogocelowowo szarnirno soczlennowo szassi so smennym oborudowaniem. Stroitelnyje i Dororznyje Masziny $9 / 1990$

[6] Lopatka M.J., Muszynski T.: Research of High Speed Articulated Wheel Tool-Carrier Steering Systems. 9th European Regional Conference of the ISTVS (The Intenational Society of TerreinVehicle Systems), 8 $\div 11.09 .2003$. Harper Adams University College. England2003, pp. 261-272

[7] Lopatka M.J., Muszynski T.,: Research of the Snaking Phenomenon to Improve Directional Stability of Remote Controlled Articulated Wheel Tool-Carrier". 20th International Symposium on Automation and Robootics Construction (ISARC), $21 \div 25.09 .2003$. Technische Universiteit Eindhoven (TU/e). Netherlands 2003, pp. 95-101

[8] Lopatka M.J., Muszynski T.: Influence of hydrostatic power steering units type on road stability articulated tool-carrier. $3^{\text {rd }}$ Fluid Power Net International (FPNI) - PhD Symposium. Terrassa, Spain 2004, pp. 329-340

[9] Lopatka M.J.: Investigation of snaking phenomenon limitations in articulated combat equipment. Report, Military University of Technology, Warsaw 2004

[10] Malinowskij E.J., Gajcgori M.M.: Dinamika samochodnych maszin s szarnirnoj ramoj. Maszinostrojenie, Moskwa 1974

[11] Ognibene: Power steering. Hydrostatic power steering system. Form 497033 